\title{
Prevalence and prognostic impact of synchronous distant metastases in patients with hypopharynx squamous cell carcinomas: a SEER-based study
}

\author{
Yujiao $\mathrm{Li}^{1,2}$, Xiaomin $\mathrm{Ou}^{1,2}$, Chaosu $\mathrm{Hu}^{1,2}{ }^{\varpi}$ \\ 1. Department of Radiation Oncology, Fudan University Shanghai Cancer Center, Shanghai, China \\ 2. Department of Oncology, Shanghai Medical College, Shanghai, China \\ $\triangle$ Corresponding author: Pro. Chaosu Hu, Address: Fudan University Shanghai Cancer Center, 270 Dong An Road, Shanghai 200032 , China. Tel.: +86 21 \\ 64175590 1400; fax: +86 21 64174774. E-mail address: hucsu62@yahoo.com \\ (C) Ivyspring International Publisher. This is an open access article distributed under the terms of the Creative Commons Attribution (CC BY-NC) license \\ (https://creativecommons.org/licenses/by-nc/4.0/). See http://ivyspring.com/terms for full terms and conditions.
}

Received: 2018.07.16; Accepted: 2018.11.02; Published: 2019.01.01

\begin{abstract}
Background: The prognosis of hypopharynx squamous cell carcinoma (SCC) patients with distant metastasis is poor. We sought to explore prevalence and prognostic impact of synchronous distant metastases among patients with hypopharynx SCC in this study.

Methods: Patients with histologically proven hypopharynx SCC were extracted from the Surveillance, Epidemiology and End Results (SEER) database between 2010 and 2014. We examined the relationship between tumor factors and distant metastases using Chi-squared tests and we evaluated the association between survival and different variables using the methods of Kaplan-Meier. Univariate analysis was performed using the log-rank test. Multivariate analyses with the Cox proportional hazards model were used to test the independent significance of the predictors, and two-tailed $p$-values less than 0.05 were considered statistically significant.

Results: We finally identified 1780 patients who were diagnosed with hypopharynx SCC and the most frequent site of distant metastases was lung. Some clinical characteristics, including age, gender, race, histological grade, $\mathrm{T}$ classification and $\mathrm{N}$ classification were independent risk factors. Higher $\mathrm{T}$ or $\mathrm{N}$ category, posterior wall of hypopharynx cancers and multiple sites of metastases were associated with poorer overall survival. For cancer-specific survival, elderly patients with higher $\mathrm{T}$ category, advanced $\mathrm{N}$ category, posterior wall of hypopharynx cancers, multiple sites of metastases and no surgery therapies to the primary tumor were associated with worse survival.

Conclusion: This is the first SEER analysis assessing prevalence and prognostic impact of synchronous distant metastases in a large cohort of patients with hypopharynx SCC. Poorer prognosis was associated with elderly patients, higher $\mathrm{T}$ category, advanced $\mathrm{N}$ category, posterior wall of hypopharynx cancers, no surgery therapies to the primary tumor and more metastatic sites
\end{abstract}

Key words: synchronous distant metastases, hypopharynx squamous cell carcinomas, metastatic pattern, seer database, prognostic value

\section{Introduction}

Oral carcinomas are the sixth most common cancers in the world, after cancers of the lung, breast, colorectal, prostate and gastric cancers [1]. Squamous cell carcinoma (SCC) of the hypopharynx is less prevalent than at most other major sites of the head and neck, such as the oral cavity, larynx and oropharynx, and accounts for approximately 3\% to $5 \%$ of all head and neck SCC [2,3]. Hypopharynx SCCs have their own specific and unique characteristics and considerations regarding treatment. Although the incidence of distant metastasis in hypopharynx SCC is low compared to 
other cancer types, such as breast or lung cancer, distant metastasis is a major determinant of management and prognosis. Treatment algorithms for hypopharynx SCC have been based on a multitude of factors including tumor characteristics (histology, biology and stage) and patient characteristics (co-morbidity and performance status). Despite evolution in management, the overall survival of patients with distant metastases has not improved significantly during the past 20 years [4].

Site and burden of distant metastatic disease are interesting, easy to assess clinical markers that can help triage patients into good and poor prognosis categories. Moreover, specific clinical patterns of distant metastasis can be linked to some baseline epidemiological and clinical factors as well as biologic and molecular factors. Population based databases can be utilized to answer many of the above questions. As far as we know, studies describing the clinical correlates and prognostic value of distant metastases in hypopharynx SCC systematically are few and we sought to explore prevalence and prognostic impact of synchronous distant metastases among patients with hypopharynx SCC in this study.

\section{Materials and Methods}

\section{Cohort population}

The SEER program is the largest publicly available cancer dataset, which contains data on patient demographics, tumor characteristics, first course of treatment, and follow-up information. However, SEER does not currently include any information on location of metastases in the standard research data until 2010. The criteria defined for inclusion in this study were primary histologically confirmed hypopharynx SCC and diagnosed between 2010 and 2014. We excluded a total of 244 patients mainly because of unknown pathology type of tumor, lack of racial information, unstaged tumors or 'blanks' metastatic site. A total of 1780 hypopharynx SCC patients were included in the final sample for this analysis.

\section{Statistical analysis}

The patients' demographic and tumor characteristics were summarized with descriptive statistics. We examined the relationship between these factors and distant metastases using Chi-squared tests.

Survival was defined as the number of months between the date of diagnosis and the date of death of any causes (OS) or of their cancer (CSS). For analysis of overall survival, the time from diagnosis until the end of the follow-up was used together with the information whether a patient died or not. For cancer-specific survival, CSS was calculated from the date of diagnosis to the date of cancer specific death whereas other deaths unrelated to hypopharynx SCC were censored. The censoring was based on the coding of these endpoints in the SEER database (alive, cancer-associated death, other death). We evaluated the association between survival and different variables using the methods of Kaplan-Meier. Univariate analysis was performed using the log-rank test. Multivariate analyses with the Cox proportional hazards model were used to test the independent significance of the predictors.

Two-sided $P$ value $<0.05$ was considered statistically significant and confidence intervals (CIs) were set as $95 \%$. All of statistical analyses were performed using SPSS 19.0 (SPSS, Chicago, IL).

\section{Results}

\section{Clinical Characteristics of all Patients}

Among the 1780 patients, there were 1452 males $(81.6 \%)$ and 328 females (18.4\%). Median age was 64, with a range of $25-95$. About $4.9 \%$ tumors were well differentiated (Grade I), while $51.1 \%$ were moderately differentiated (Grade II) and $44.0 \%$ were poorly differentiated or undifferentiated (Grade III). 62.2\% $(n=1107)$ of the patients were stage IV (Figure 1).

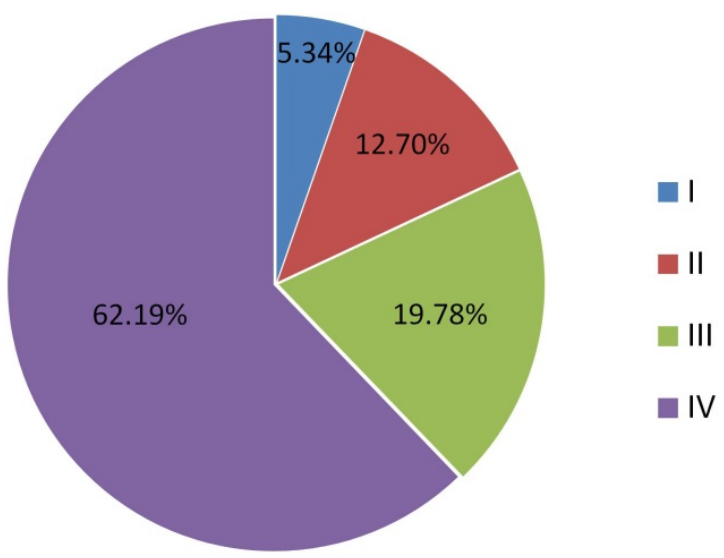

Figure 1. Proportions of different stages in selected patients

According to the 7th edition of UICC/AJCC Staging System, 197 patients $(11.1 \%)$ were T1, 619 patients $(34.8 \%)$ were $\mathrm{T} 2,459$ patients $(25.8 \%)$ were T3, 341 patients $(19.2 \%)$ were T4a, and 164 patients $(9.2 \%)$ were $\mathrm{T} 4 \mathrm{~b}$. With regard to $\mathrm{N}$ classifications, 606 patients $(34.0 \%)$ were N0, 309 patients $(17.4 \%)$ were $\mathrm{N} 1,76$ patients $(4.3 \%)$ were $\mathrm{N} 2 \mathrm{a}, 428$ patients $(24.0 \%)$ were N2b, 282 patients (15.8\%) were N2c, and 79 patients $(4.4 \%)$ were N3. Patients' characteristics are listed in Table 1. Patients with pyriform sinus carcinoma was almost half of all patients (49.9\%) when diagnosed. 
Table 1. Patients' characteristics.

\begin{tabular}{|c|c|c|}
\hline & number of patients & $\%$ \\
\hline \multicolumn{3}{|l|}{ Age } \\
\hline Median & 64 & \\
\hline Range & $25-95$ & \\
\hline \multicolumn{3}{|l|}{ Gender } \\
\hline Male & 1452 & 81.6 \\
\hline Female & 328 & 18.4 \\
\hline \multicolumn{3}{|l|}{ Race } \\
\hline Caucasian & 1378 & 77.4 \\
\hline Asian & 117 & 6.6 \\
\hline African American & 285 & 16.0 \\
\hline \multicolumn{3}{|l|}{ T classification } \\
\hline $\mathrm{T} 1$ & 197 & 11.1 \\
\hline $\mathrm{T} 2$ & 619 & 34.8 \\
\hline T3 & 459 & 25.8 \\
\hline $\mathrm{T} 4 \mathrm{a}$ & 341 & 19.2 \\
\hline $\mathrm{T} 4 \mathrm{~b}$ & 164 & 9.2 \\
\hline \multicolumn{3}{|l|}{$\mathrm{N}$ classification } \\
\hline No & 606 & 34.0 \\
\hline N1 & 309 & 17.4 \\
\hline $\mathrm{N} 2 \mathrm{a}$ & 76 & 4.3 \\
\hline $\mathrm{N} 2 \mathrm{~b}$ & 428 & 24.0 \\
\hline $\mathrm{N} 2 \mathrm{c}$ & 282 & 15.8 \\
\hline N3 & 79 & 4.4 \\
\hline \multicolumn{3}{|l|}{ Grade } \\
\hline 1 & 88 & 4.9 \\
\hline 2 & 909 & 51.1 \\
\hline 3 & 783 & 44.0 \\
\hline \multicolumn{3}{|l|}{ Surgery therapy } \\
\hline Yes & 451 & 25.3 \\
\hline No & 1329 & 74.7 \\
\hline \multicolumn{3}{|l|}{ Tumor location } \\
\hline Pyriform sinus & 889 & 49.9 \\
\hline Postcricoid region & 63 & 3.5 \\
\hline Aryepiglottic fold, hypopharyngeal & 141 & 7.9 \\
\hline Posterior wall of hypopharynx & 134 & 7.5 \\
\hline Overlapping lesion of hypopharynx & 58 & 3.3 \\
\hline Hypopharynx, NOS & 495 & 27.8 \\
\hline
\end{tabular}

Abbreviations: NOS: not otherwise specified

\section{Metastasis pattern}

The database only had metastatic information related to liver, lung, bone and brain metastasis. In the patients of all-stage hypopharynx SCC, the most frequent site of synchronous distant metastases at initial diagnosis was lung $(\mathrm{n}=72)$, followed by liver $(n=19)$ and bone $(n=18)$. Metastasis to brain $(n=6)$ was the least among the four sites.

As shown in Table 2, histological grade of tumor was found to be independently associated with lung metastases and poorer differentiation was an independent prognostic parameter for higher incidence of lung metastasis ( $p=0.001)$. In addition, we found that $\mathrm{T}$ classification was also an independent parameter for metastatic diseases. A higher T category was associated with higher incidence of lung, bone and brain metastasis $(\mathrm{p}=0.004, \mathrm{p}<0.001$ and $\mathrm{p}=0.010$, respectively). The same results were found in $\mathrm{N}$ category in lung and bone metastasis $(\mathrm{p}<0.001$ and $\mathrm{p}=0.019$, respectively).

What's more, lung metastatic diseases were associated with Caucasian and male gender $(\mathrm{p}=0.013$ and $\mathrm{p}=0.024$, respectively). Pyriform sinus carcinoma was associated with lower incidence of liver metastasis $(\mathrm{p}=0.041)$.

Table 2. Demographic and clinical features of patients with and without metastases

\begin{tabular}{|c|c|c|c|c|c|c|c|c|c|c|c|c|}
\hline \multirow[t]{2}{*}{ Features } & \multicolumn{2}{|c|}{ Lung Metastasis } & \multirow{2}{*}{$\begin{array}{l}P \\
\text { value }\end{array}$} & \multicolumn{2}{|c|}{ Liver Metastasis } & \multirow{2}{*}{$\begin{array}{l}P \\
\text { value }\end{array}$} & \multicolumn{2}{|c|}{ Bone Metastasis } & \multirow{2}{*}{$\begin{array}{l}\mathrm{P} \\
\text { value }\end{array}$} & \multicolumn{2}{|c|}{ Brain Metastasis } & \multirow{2}{*}{$\begin{array}{l}P \\
\text { value }\end{array}$} \\
\hline & No & Yes & & No & Yes & & No & Yes & & No & Yes & \\
\hline Gender & & & 0.024 & & & 0.999 & & & 0.618 & & & 0.600 \\
\hline Male & 1386 & 66 & & 1436 & 16 & & 1436 & 16 & & 1446 & 6 & \\
\hline Female & 322 & 6 & & 325 & 3 & & 326 & 2 & & 328 & 0 & \\
\hline Age & & & 0.558 & & & 0.764 & & & 0.865 & & & 0.969 \\
\hline$\leq 64$ & 865 & 39 & & 895 & 9 & & 894 & 10 & & 901 & 3 & \\
\hline$>64$ & 843 & 33 & & 866 & 10 & & 868 & 8 & & 873 & 3 & \\
\hline Race & & & 0.013 & & & 0.327 & & & 0.767 & & & 0.034 \\
\hline Caucasian & 1332 & 46 & & 1366 & 12 & & 1365 & 13 & & 1376 & 2 & \\
\hline Asian & 111 & 6 & & 115 & 2 & & 116 & 1 & & 116 & 1 & \\
\hline $\begin{array}{l}\text { African } \\
\text { American }\end{array}$ & 265 & 20 & & 280 & 5 & & 281 & 4 & & 282 & 3 & \\
\hline Grade & & & 0.001 & & & 0.191 & & & 0.615 & & & 0.149 \\
\hline 1 & 87 & 1 & & 88 & 0 & & 88 & 0 & & 88 & 0 & \\
\hline 2 & 885 & 24 & & 902 & 7 & & 899 & 10 & & 908 & 1 & \\
\hline 3 & 736 & 47 & & 771 & 12 & & 775 & 8 & & 778 & 5 & \\
\hline T classification & & & 0.004 & & & 0.280 & & & $<0.001$ & & & 0.010 \\
\hline $\mathrm{T} 1$ & 196 & 1 & & 195 & 2 & & 195 & 2 & & 197 & 0 & \\
\hline $\mathrm{T} 2$ & 595 & 24 & & 611 & 8 & & 616 & 3 & & 618 & 1 & \\
\hline T3 & 442 & 17 & & 457 & 2 & & 457 & 2 & & 457 & 2 & \\
\hline $\mathrm{T} 4 \mathrm{a}$ & 325 & 16 & & 338 & 3 & & 337 & 4 & & 341 & 0 & \\
\hline $\mathrm{T} 4 \mathrm{~b}$ & 150 & 14 & & 160 & 4 & & 157 & 7 & & 161 & 3 & \\
\hline $\mathrm{N}$ classification & & & $<0.001$ & & & 0.221 & & & 0.019 & & & 0.211 \\
\hline N0 & 601 & 5 & & 602 & 4 & & 604 & 2 & & 606 & 0 & \\
\hline N1 & 295 & 14 & & 306 & 3 & & 301 & 8 & & 308 & 1 & \\
\hline $\mathrm{N} 2 \mathrm{a}$ & 74 & 2 & & 75 & 1 & & 76 & 0 & & 76 & 0 & \\
\hline $\mathrm{N} 2 \mathrm{~b}$ & 402 & 26 & & 424 & 4 & & 425 & 3 & & 424 & 4 & \\
\hline $\mathrm{N} 2 \mathrm{c}$ & 265 & 17 & & 278 & 4 & & 279 & 3 & & 281 & 1 & \\
\hline N3 & 71 & 8 & & 76 & 3 & & 77 & 2 & & 79 & 0 & \\
\hline
\end{tabular}




\begin{tabular}{|c|c|c|c|c|c|c|c|c|c|c|c|c|}
\hline \multirow[t]{2}{*}{ Features } & \multicolumn{2}{|c|}{ Lung Metastasis } & \multirow{2}{*}{$\begin{array}{l}P \\
\text { value }\end{array}$} & \multicolumn{2}{|c|}{ Liver Metastasis } & \multirow{2}{*}{$\begin{array}{l}\mathrm{P} \\
\text { value }\end{array}$} & \multicolumn{2}{|c|}{ Bone Metastasis } & \multirow{2}{*}{$\begin{array}{l}P \\
\text { value }\end{array}$} & \multicolumn{2}{|c|}{ Brain Metastasis } & \multirow{2}{*}{$\begin{array}{l}\mathrm{P} \\
\text { value }\end{array}$} \\
\hline & No & Yes & & No & Yes & & No & Yes & & No & Yes & \\
\hline Tumor location & & & 0.271 & & & 0.041 & & & 0.629 & & & 0.884 \\
\hline Pyriform sinus & 853 & 36 & & 886 & 3 & & 881 & 8 & & 885 & 4 & \\
\hline Postcricoid region & 62 & 1 & & 62 & 1 & & 62 & 1 & & 63 & 0 & \\
\hline $\begin{array}{l}\text { Aryepiglottic fold, } \\
\text { hypopharyngeal }\end{array}$ & 139 & 2 & & 138 & 3 & & 141 & 0 & & 141 & 0 & \\
\hline $\begin{array}{l}\text { Posterior wall of } \\
\text { hypopharynx }\end{array}$ & 130 & 4 & & 131 & 3 & & 132 & 2 & & 134 & 0 & \\
\hline $\begin{array}{l}\text { Overlapping lesion of } \\
\text { hypopharynx }\end{array}$ & 54 & 4 & & 56 & 2 & & 58 & 0 & & 58 & 0 & \\
\hline Hypopharynx, NOS & 470 & 25 & & 488 & 7 & & 488 & 7 & & 493 & 2 & \\
\hline
\end{tabular}

Abbreviations: NOS: not otherwise specified

Table 3. Univariate analysis of OS and CSS in hypopharynx SCC patients

\begin{tabular}{|c|c|c|c|c|}
\hline \multirow[t]{2}{*}{ Prognostic factor } & \multicolumn{2}{|c|}{ 1-y overall survival } & \multicolumn{2}{|c|}{$\begin{array}{l}\text { 1-y cancer-specific } \\
\text { survival }\end{array}$} \\
\hline & $\%$ & $\mathrm{p}$ & $\%$ & $\mathrm{p}$ \\
\hline Gender & & 0.253 & & 0.117 \\
\hline Male & 67.2 & & 69.6 & \\
\hline Female & 68.1 & & 74.1 & \\
\hline Age & & $<0.001$ & & 0.004 \\
\hline$\leq 64$ & 72.2 & & 73.7 & \\
\hline$>64$ & 62.4 & & 65.4 & \\
\hline Race & & $<0.001$ & & $<0.001$ \\
\hline Caucasian & 69.9 & & 73.2 & \\
\hline Asian & 66.8 & & 72.8 & \\
\hline African American & 55.5 & & 56.1 & \\
\hline Grade & & 0.937 & & 0.996 \\
\hline 1 & 65.8 & & 69.5 & \\
\hline 2 & 67.4 & & 70.7 & \\
\hline 3 & 67.5 & & 70.1 & \\
\hline T classification & & $<0.001$ & & $<0.001$ \\
\hline $\mathrm{T} 1$ & 85.8 & & 89.8 & \\
\hline T2 & 74.6 & & 77.0 & \\
\hline $\mathrm{T} 3$ & 63.1 & & 69.6 & \\
\hline T4a & 58.5 & & 60.3 & \\
\hline $\mathrm{T} 4 \mathrm{~b}$ & 50.0 & & 52.3 & \\
\hline $\mathrm{N}$ classification & & $<0.001$ & & $<0.001$ \\
\hline No & 72.3 & & 80.4 & \\
\hline N1 & 68.8 & & 71.4 & \\
\hline $\mathrm{N} 2 \mathrm{a}$ & 65.3 & & 71.5 & \\
\hline $\mathrm{N} 2 \mathrm{~b}$ & 67.8 & & 73.2 & \\
\hline $\mathrm{N} 2 \mathrm{c}$ & 59.7 & & 56.5 & \\
\hline N3 & 50.6 & & 51.0 & \\
\hline Tumor location & & $<0.001$ & & 0.002 \\
\hline Pyriform sinus & 72.0 & & 74.4 & \\
\hline Postcricoid region & 66.1 & & 74.9 & \\
\hline Aryepiglottic fold, hypopharyngeal & 77.4 & & 78.3 & \\
\hline Posterior wall of hypopharynx & 59.7 & & 59.0 & \\
\hline Overlapping lesion of hypopharynx & 58.3 & & 62.6 & \\
\hline Hypopharynx, NOS & 59.5 & & 64.2 & \\
\hline Surgery therapy & & $<0.001$ & & $<0.001$ \\
\hline Yes & 78.6 & & 82.5 & \\
\hline No & 63.6 & & 67.4 & \\
\hline Distant metastases & & $<0.001$ & & $<0.001$ \\
\hline No & 69.5 & & 73.1 & \\
\hline Single & 32.0 & & 30.8 & \\
\hline Multiple & 22.1 & & 21.4 & \\
\hline
\end{tabular}

Abbreviations: NOS: not otherwise specified

\section{Survival}

The median follow-up time was 13.0 months, with a range from 0 month to 59.0 months. For patients alive at the end of follow-up, the median follow-up time was 19.0 months, with a range from 0 month to 59 months. Since the time of follow-up is short in current study, we only estimated the 1-year
OS and CSS for patients with different metastases. The 1-year OS was $33.4 \%, 17.1 \%, 18.5 \%$ and $16.7 \%$ for patients with lung, liver, bone and brain metastasis, respectively. The 1-year CSS was 32.3\%, 17.6\%, 12.5\% and $33.3 \%$ for patients with lung, liver, bone and brain metastasis, respectively.

On univariate analysis, age, race, tumor location, $\mathrm{T}$ classification, $\mathrm{N}$ classification, distant metastases and surgery therapies to the primary tumor could influence OS and CSS among patients with hypopharynx SCC (Table 3).

Multivariate models controlling for different variables demonstrated that age, race, tumor location, $\mathrm{T}$ classification, $\mathrm{N}$ classification, distant metastases and surgery therapies to the primary tumor were independent prognostic factors of OS and CSS (Table 4). Elderly patients with higher $\mathrm{T}$ category, higher $\mathrm{N}$ category, posterior wall of hypopharynx cancers, multiple sites of metastases and no surgery therapies to the primary tumor were more likely to reduce life expectancy.

In our study, 5-year overall survival are 53.1\% and $29.2 \%$ for localized and regional hypopharynx SCC patients, respectively, which are much higher than metastatic hypopharynx SCC patients $(24.6 \%)$. The same results were found in CSS (Figure 2).

\section{Discussion}

The current analysis has pointed out some interesting correlations between some baseline criteria and the patterns of distant metastases. For example, lung metastatic diseases were associated with male gender and maybe the lifestyles (smoking and alcohol drinking) could partly explain the observed sex-based differences. Most patients when diagnosed have advanced-stage disease and $81.97 \%$ of the patients have stage III or IV disease at presentation (Figure 1), which were consistent with many other studies [4-6]. Higher $\mathrm{T}$ categories are observed in patients presenting with $\mathrm{M}+$ disease as opposed to M0 and advanced regional disease (N3 disease) increased the risk of distant metastases. 
A

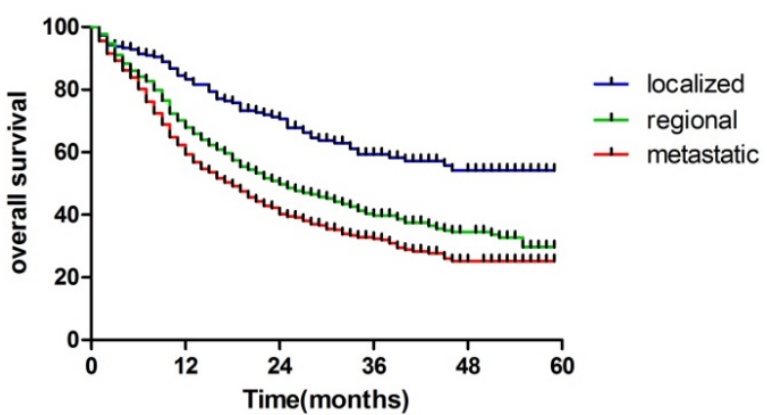

B

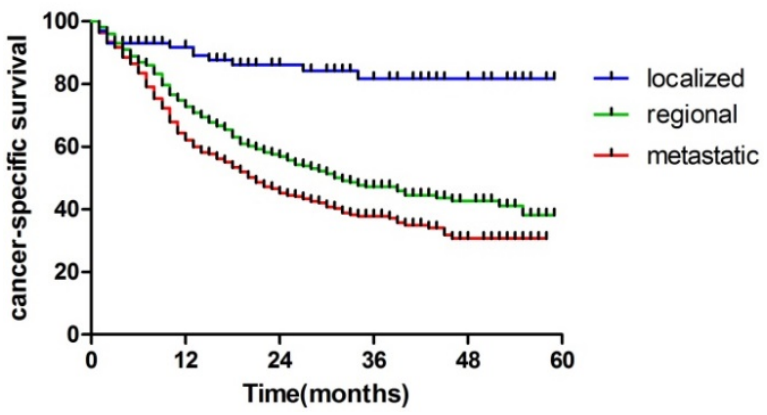

Figure 2. Kaplan-Meier analysis of OS and CSS in localized, regional and metastatic hypopharynx SCC patients. A, OS in localized, regional and metastatic hypopharynx SCC patients (log rank $\mathrm{P}<0.001)$. B, CSS in localized, regional and metastatic hypopharynx SCC patients (log rank $P<0.001)$.
Moreover, in current study, tumor location is another risk factor for distant metastatic diseases. Lesions of the hypopharynx are subdivided into the aryepiglottic fold, pyriform sinus, and posterior hypopharyngeal wall by anatomical location $[7,8]$. The incidence of postcricoid carcinoma was low (3.5\% in our study). Most postcricoid tumors were advanced pyriform fossa tumors. Therefore, postcricoid tumors were amalgamated with two or three wallapex tumors of the pyriform fossa. Pyriform sinus carcinoma was associated with lower incidence of liver metastasis $(p=0.041)$ and patients with lateral wall disease had higher survival than patients with posterior wall cancers ( $\mathrm{p}<0.001)$.

We found higher rates of synchronous distant metastases due to the development of diagnostic techniques. In autopsy findings, lung, liver and bone were the most frequent sites of distant metastases and no brain metastasis was found $[9,10]$. What is different is that distant metastases were much more common when autopsy due to the inclusion of metastases after treatment, for example, the highest autopsy distant metastatic rate was $60 \%$ in tumors of the hypopharynx [11] but the patterns of metastases were similar.

Table 4. Impact of prognostic factors for OS and CSS by multivariate analyses.

\begin{tabular}{|c|c|c|c|c|c|c|}
\hline \multirow[t]{2}{*}{ Prognostic factor } & \multicolumn{3}{|c|}{ overall survival } & \multicolumn{3}{|c|}{ cancer-specific survival } \\
\hline & $P$ value & HR & $95 \% \mathrm{CI}$ & $P$ value & HR & $95 \% \mathrm{CI}$ \\
\hline Age & 0.00 & 1.55 & $1.36-1.78$ & 0.00 & 1.44 & $1.20-1.73$ \\
\hline Race & 0.00 & & & 0.00 & & \\
\hline Caucasian & & 1(reference) & & & 1(reference) & \\
\hline Asian & & 1.07 & $0.81-1.41$ & & 0.93 & $0.64-1.35$ \\
\hline African American & & 1.47 & $1.24-1.75$ & & 1.40 & $1.12-1.75$ \\
\hline T classification & 0.00 & & & 0.00 & & \\
\hline $\mathrm{T} 1$ & & 1(reference) & & & 1(reference) & \\
\hline $\mathrm{T} 2$ & & 1.67 & $1.23-2.25$ & & 2.10 & $1.29-3.41$ \\
\hline $\mathrm{T} 3$ & & 2.34 & $1.72-3.18$ & & 2.99 & $1.84-4.86$ \\
\hline T4a & & 3.32 & $2.43-4.54$ & & 4.46 & $2.73-7.29$ \\
\hline $\mathrm{T} 4 \mathrm{~b}$ & & 3.21 & $2.28-4.53$ & & 4.19 & $2.49-7.05$ \\
\hline $\mathrm{N}$ classification & 0.01 & & & 0.00 & & \\
\hline No & & 1(reference) & & & 1(reference) & \\
\hline N1 & & 1.05 & $0.86-1.29$ & & 1.16 & $0.85-1.57$ \\
\hline $\mathrm{N} 2 \mathrm{a}$ & & 1.25 & $0.87-1.78$ & & 1.53 & $0.97-2.43$ \\
\hline $\mathrm{N} 2 \mathrm{~b}$ & & 1.12 & $0.93-1.35$ & & 1.30 & $1.00-1.69$ \\
\hline $\mathrm{N} 2 \mathrm{C}$ & & 1.17 & $0.95-1.43$ & & 1.64 & $1.25-2.17$ \\
\hline N3 & & 1.82 & $1.33-2.48$ & & 2.44 & $1.65-3.61$ \\
\hline Tumor location & 0.00 & & & 0.02 & & \\
\hline Pyriform sinus & & 1(reference) & & & 1(reference) & \\
\hline Postcricoid region & & 1.46 & $1.02-2.11$ & & 1.57 & $0.94-2.64$ \\
\hline Aryepiglottic fold, hypopharyngeal & & 1.03 & $0.78-1.36$ & & 0.86 & $0.57-1.29$ \\
\hline Posterior wall of hypopharynx & & 1.37 & $1.07-1.76$ & & 1.51 & $1.08-2.10$ \\
\hline Overlapping lesion of hypopharynx & & 1.15 & $0.77-1.71$ & & 1.31 & $0.80-2.15$ \\
\hline Hypopharynx, NOS & & 1.29 & $1.10-1.51$ & & 1.30 & $1.06-1.60$ \\
\hline Surgery therapy & 0.00 & 1.45 & $1.23-1.70$ & 0.00 & 1.51 & $1.19-1.93$ \\
\hline Distant metastases & 0.00 & & & 0.00 & & \\
\hline No & & 1(reference) & & & 1(reference) & \\
\hline Single & & 2.24 & $1.71-2.93$ & & 2.36 & $1.68-3.31$ \\
\hline Multiple & & 2.74 & $1.60-4.70$ & & 2.87 & $1.59-5.16$ \\
\hline
\end{tabular}


Compared with colorectal cancer [12] and breast cancer [13], prognosis of metastatic hypopharynx SCC is always dismal [14], which is not so much due to malignant biological behaviors of hypopharynx SCC as to lack of effective systemic treatment. What's worse, for metastatic hypopharynx SCC patients, this a bit less definitively since often treated with combination chemoyherapy, evidence for survival benefit cetuximab, advent of nivolumab 2 nd line.

In our study, number of metastatic sites was an independent prognostic parameter both for OS and CSS. Many studies have indicated that patients with oligometastases may benefit from local aggressive therapy and increase their life expectancy [15]. However, absence of information about performance status of the patients in the current analysis should be taken into account when interpreting these findings as differences in baseline performance may have led to selection bias in the choice of local treatments (i.e. patients with better performance status are being referred to surgery more likely than patients with unfavorable performance status). What's more, there is a selection bias of oligometastatic disease, which indeed surgeons have been operating primaries in patients with low $\mathrm{M}+$ burden, versus extensive metastatic disease, and this bias is hard to filter out. In addition, benefits of surgery of the primary tumor in cases of a metastatic solid tumor have been suggested for a number of solid tumors including metastatic pancreatic adenocarcinoma and neuroendocrine tumors and metastatic hepatocellular carcinoma [15-18]. This strategy is currently being evaluated in a number of ongoing studies for metastatic breast cancer $[19,20]$.

Furthermore, early diagnosis and treatment is of particular importance. In our study, 5-year overall survival are $53.1 \%$ and $29.2 \%$ for localized and regional hypopharynx SCC patients, respectively, which are much higher than metastatic hypopharynx SCC patients $(24.6 \%)$. The same results were found in CSS (Figure 2).

Better understanding of clinical correlates and prognostic value of distant metastases is helpful in the clinical decision-making process. Since lung is the most frequent site of distant metastases, contrast enhancement computed tomography (CT) on chest should be maintained according to NCCN guideline [21]. And for patients with high risk factors of specific site of metastasis, imaging of other sites should be applied. Diagnosis of metastasis is essential not only for staging, but also for further systematic treatment. With the development of medical technology, quantities of therapy methods, including surgery and stereotactic body radiotherapy (SBRT), have been applied to clinical practice for metastases sites and proved to be effective [15].

As far as we know, this is the first SEER analysis assessing clinical correlates and prognostic value of distant metastases in a large cohort of patients with hypopharynx SCC. However, there are still some limitations. Firstly, the details about metastases, such as sizes and exact metastatic lesion quantity in specific organ, were not included. Secondly, it is lack of information about systemic therapy options the patients have received. The use of chemoradiotherapy for the purpose of organ preservation has been increasing [4,22-24], especially in recent years, but SEER does not currently include any information in the standard research data. Thirdly, all information on metastases is from their first diagnosis and lack of following information, including treatment modalities of the patients which may confound the assessment of overall survival analysis. Thus, cancer-specific survival has been evaluated as a primary outcome in this study to avoid the confounding effect of non-cancer deaths.

\section{Conclusion}

In the patients of hypopharynx SCC, lung was the most frequent site of distant metastases. Poorer prognosis was associated with elderly patients, higher $\mathrm{T}$ category, advanced $\mathrm{N}$ category, posterior wall of hypopharynx cancers, no surgery therapies to the primary tumor and more metastatic sites.

\section{Acknowledgements}

We acknowledge the support of the Department of Radiation Oncology, Fudan University Shanghai Cancer Center. The views expressed in this publication are those of the authors.

\section{Ethical Approval and Informed Consent}

All procedures performed in studies involving human participants were in accordance with the ethical standards of Fudan University Shanghai Cancer Center Ethics committee and with the 1964 Helsinki declaration and its later amendments or comparable ethical standards. The experimental protocols were also approved by Fudan University Shanghai Cancer Center Ethics committee. Written informed consent was obtained from all individual participants included in the study.

\section{Author Contributions}

Yujiao $\mathrm{Li}$, Xiaomin $\mathrm{Ou}$ and Chaosu $\mathrm{Hu}$ have made substantial contributions to all of the following: (1) the conception and design of the study, or acquisition of data, or analysis and interpretation of data, (2) drafting the article or revising it critically for 
important intellectual content, (3) final approval of the version to be submitted.

\section{Competing Interests}

The authors have declared that no competing interest exists.

\section{References}

1. Torre LA, Bray F, Siegel RL, Ferlay J, Lortet-Tieulent J, Jemal A. Global cancer statistics, 2012. CA Cancer J Clin. 2015;65:87-108.

2. Cooper JS, Porter K, Mallin K, Hoffman HT, Weber RS, Ang KK, et al. National Cancer Database report on cancer of the head and neck: 10 -year update. Head Neck. 2009;31:748-58

3. Hall SF, Groome PA, Irish J, O'Sullivan B. The natural history of patients with squamous cell carcinoma of the hypopharynx. LARYNGOSCOPE. 2008;118:1362-71.

4. Takes RP, Strojan P, Silver CE, Bradley PJ, Haigentz MJ, Wolf GT, et al. Current trends in initial management of hypopharyngeal cancer: the declining use of open surgery. Head Neck. 2012;34:270-81.

5. Rodrigo JP, Martínez P, Allonca E, Alonso-Durán L, Suárez C, Astudillo A, et al. Immunohistochemical markers of distant metastasis in laryngeal and hypopharyngeal squamous cell carcinomas. CLIN EXP METASTAS. 2014;31:317-25.

6. Takes RP, Rinaldo A, Silver CE, Haigentz M, Woolgar JA, Triantafyllou A, et al. Distant metastases from head and neck squamous cell carcinoma. Part I. Basic aspects. ORAL ONCOL. 2012;48:775-9.

7. Spector JG, Sessions DG, Emami B, Simpson J, Haughey B, Fredrickson JM. Squamous cell carcinomas of the aryepiglottic fold: therapeutic results and long-term follow-up. LARYNGOSCOPE. 1995;105:734-46.

8. Spector JG, Sessions DG, Emami B, Simpson J, Haughey B, Harvey J, et al. Squamous cell carcinoma of the pyriform sinus: a nonrandomized comparison of therapeutic modalities and long-term results. LARYNGOSCOPE. 1995;105:397-406.

9. Spector JG, Sessions DG, Haughey BH, Chao KS, Simpson J, El MS, et al. Delayed regional metastases, distant metastases, and second primary malignancies in squamous cell carcinomas of the larynx and hypopharynx. LARYNGOSCOPE. 2001;111:1079-87.

10. Bień S, Kamiński B, Żyłka S, Meżyk R, Piasta Z. Evolution of the epidemiology and clinical characteristics of larynx and hypopharynx carcinoma in Poland from 1991 to 2001. EUR ARCH OTO-RHINO-L. 2008;265:39-46.

11. Kotwall C, Sako K, Razack MS, Rao U, Bakamjian V, Shedd DP. Metastatic patterns in squamous cell cancer of the head and neck. AM J SURG. 1987;154:439-42

12. Institute NC. SEER Stat Fact Sheets: Colon and Rectum Cancer. Cited 4 September 2016. Available from: http://seer.cancer.gov/statfacts/html/ colorect.html. 2017.

13. Institute NC. SEER Stat Fact Sheets: Female Breast Cancer. Cited 4 September 2016. SEER 18 2006-12, All Races, Females by SEER Summary Stage 0. Available from: http://seer.cancer.gov/statfacts/html/breast.html. 2017.

14. Institute NC. SEER Stat Fact Sheets: Oral Cavity and Pharynx Cancer. Cited 4 September 2016. SEER 18 2006-12, All Races, by SEER Summary Stage 0. Available from: http://seer.cancer.gov/statfacts/html/oralcav.html. 2017.

15. Lo SS, Moffatt-Bruce SD, Dawson LA, Schwarz RE, Teh BS, Mayr NA, et al. The role of local therapy in the management of lung and liver oligometastases. NAT REV CLIN ONCOL. 2011;8:405-16.

16. Oweira H, Petrausch U, Helbling D, Schmidt J, Mannhart M, Mehrabi A, et al. Prognostic value of site-specific metastases in pancreatic adenocarcinoma: A Surveillance Epidemiology and End Results database analysis. World J Gastroenterol. 2017;23:1872-80.

17. Keutgen XM, Nilubol N, Glanville J, Sadowski SM, Liewehr DJ, Venzon DJ, et al. Resection of primary tumor site is associated with prolonged survival in metastatic nonfunctioning pancreatic neuroendocrine tumors. SURGERY. 2016:159:311-8

18. Huttner FJ, Schneider L, Tarantino I, Warschkow R, Schmied BM, Hackert T, et al. Palliative resection of the primary tumor in 442 metastasized neuroendocrine tumors of the pancreas: a population-based, propensity score-matched survival analysis. Langenbecks Arch Surg. 2015;400:715-23.

19. Shien T, Nakamura K, Shibata T, Kinoshita T, Aogi K, Fujisawa T, et al. A randomized controlled trial comparing primary tumour resection plus systemic therapy with systemic therapy alone in metastatic breast cancer (PRIM-BC): Japan Clinical Oncology Group Study JCOG1017. JPN J CLIN ONCOL. 2012;42:970-3.

20. Ruiterkamp J, Voogd AC, Tjan-Heijnen VC, Bosscha K, van der Linden YM, Rutgers EJ, et al. SUBMIT: Systemic therapy with or without up front surgery of the primary tumor in breast cancer patients with distant metastases at initial presentation. BMC Surg. 2012;12:5.

21. Network NCC. NCCN Clinical Practice Guidelines in Oncology (NCCN Guidelines $\left.{ }^{\circ}\right)$ 2016. Cited 14 September 2016. Version 1.2016: Available from: https://www.nccn.org/professionals/physician_gls/pdf/head and neck.pdf. 2016.
22. Qian W, Zhu G, Wang Y, Wang X, Ji Q, Wang Y, et al. Multi-modality management for loco-regionally advanced laryngeal and hypopharyngeal cancer: balancing the benefit of efficacy and functional preservation. MED ONCOL. 2014;31

23. Hanai N, Kawakita D, Ozawa T, Hirakawa H, Kodaira T, Hasegawa Y. Neck dissection after chemoradiotherapy for oropharyngeal and hypopharyngeal cancer: the correlation between cervical lymph node metastasis and prognosis. INT J CLIN ONCOL. 2014;19:30-7.

24. Gupta T, Chopra S, Agarwal JP, Laskar SG, D'Cruz AK, Shrivastava SK, et al. Squamous cell carcinoma of the hypopharynx: single-institution outcome analysis of a large cohort of patients treated with primary non-surgical approaches. ACTA ONCOL. 2009;48:541-8. 